\title{
ERRATUM TO “ULTRALOGICS AND PROBABILITY MODELS"
}

\author{
ROBERT A. HERRMANN
}

Received 14 January 2006; Accepted 28 March 2006

Copyright @ 2006 Hindawi Publishing Corporation. All rights reserved.

In [1, page 324], line 20 from bottom should read as follows. "If each $C_{k}$ is a finite and axiomless consequence operator, then $\Pi C_{m}$ is axiomless and finite."

Moreover, in [1, page 324], line 24 from bottom, the phrase "where at least one is axiomless" should be deleted.

\section{References}

[1] R. A. Herrmann, Ultralogics and probability models, International Journal of Mathematics and Mathematical Sciences 27 (2001), no. 5, 321-325.

Robert A. Herrmann: 44890 Rivermont Terrace 100, Ashburn, VA 20147, USA

E-mail address: rah@usna.edu 


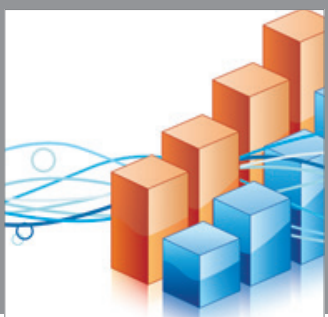

Advances in

Operations Research

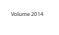

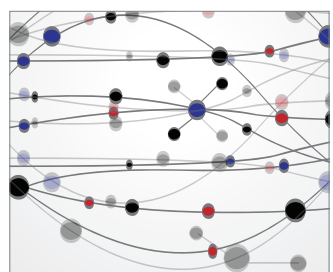

\section{The Scientific} World Journal
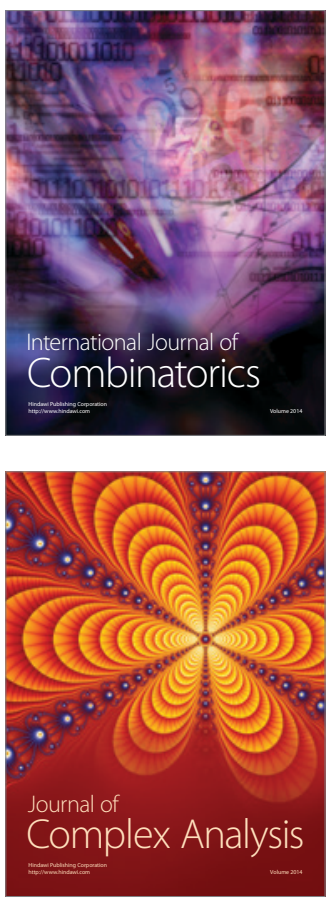

International Journal of

Mathematics and

Mathematical

Sciences
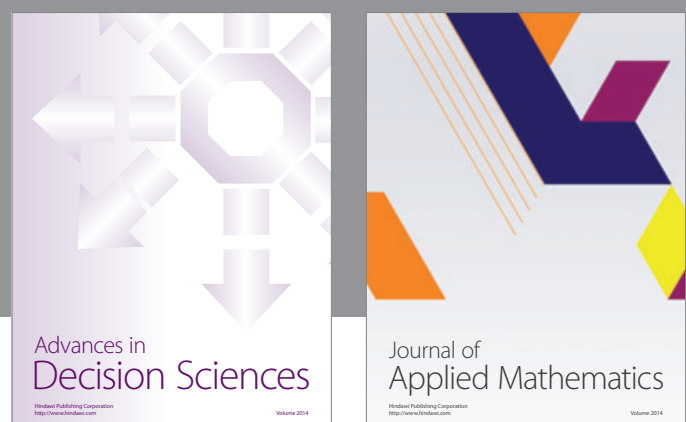

Journal of

Applied Mathematics
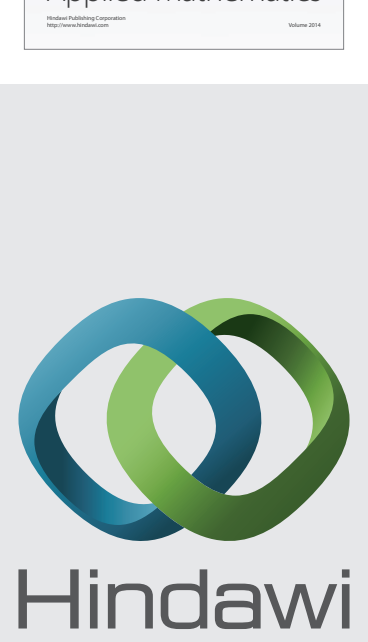

Submit your manuscripts at http://www.hindawi.com
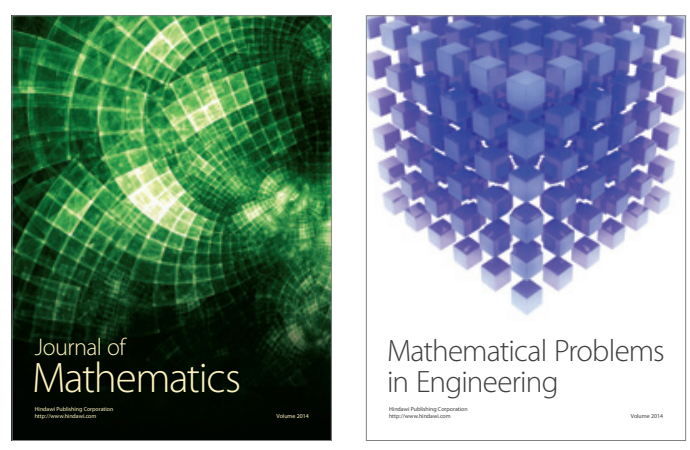

Mathematical Problems in Engineering
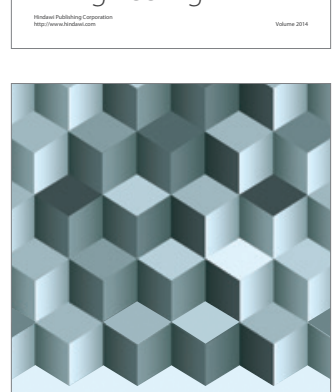

Journal of

Function Spaces
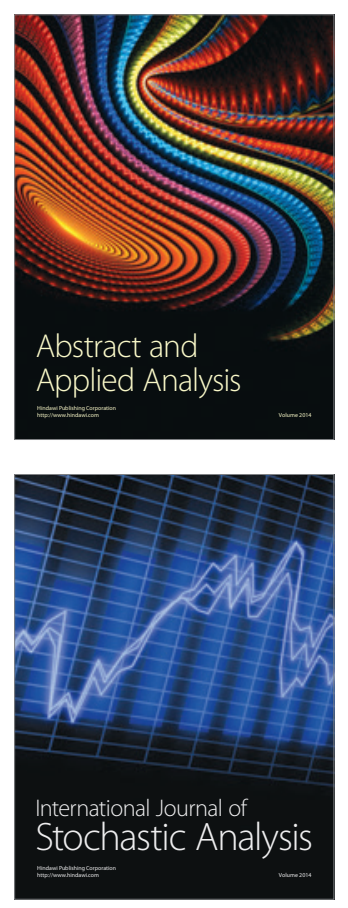

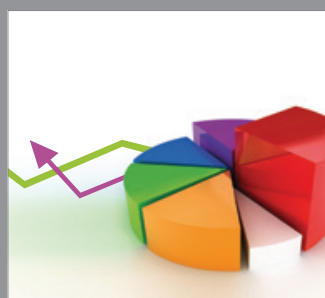

ournal of

Probability and Statistics

Promensencen
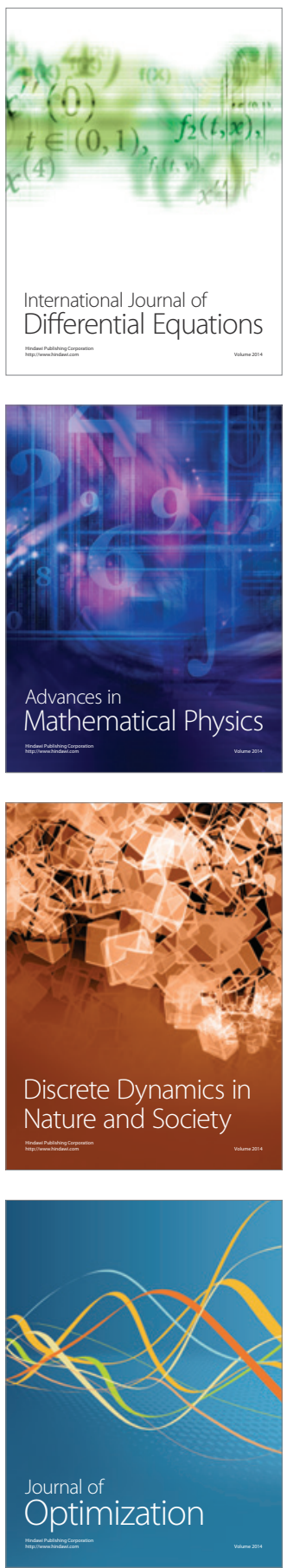